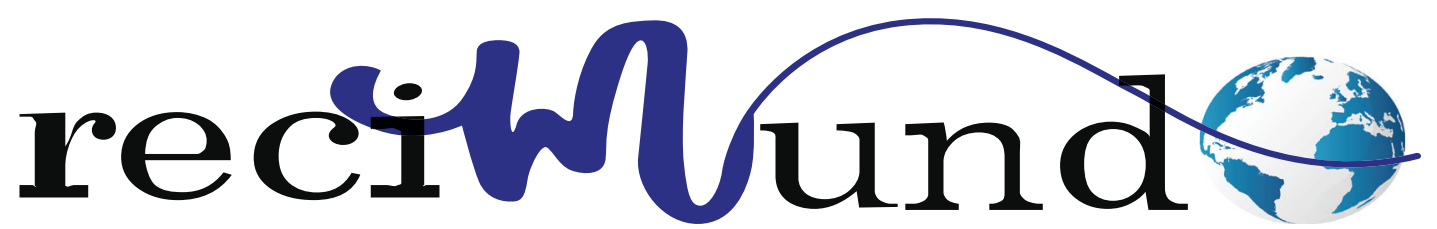

Revista Científica Mundo de la Investigación y el Conocimiento

DOI: 10.26820/recimundo/4.(4).octubre.2020.174-181

URL: http://recimundo.com/index.php/es/article/view/891

EDITORIAL: Saberes del Conocimiento

REVISTA: RECIMUNDO

ISSN: 2588-073X

TIPO DE INVESTIGACIÓN: Reporte de caso

Código UNESCO: 32 Ciencias Médicas

PAGINAS: $174-181$

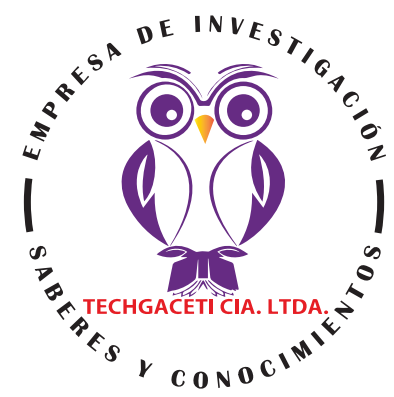

\title{
Encefalitis autoinmune por anticuerpos NMDA a propósito de un caso clínico
}

Autoimmune encephalitis due to NMDA antibodies related to a clinical case Encefalite autoimune por anticorpos NMDA relacionada a um caso clínico Jonathan Alexander Macas Noblecilla'; Lissette Liliana Muñoz Rodríguez²;

Antonio Xavier Honores Correa3; Jessica Carolina Lazo Amon ${ }^{4}$

RECIBIDO: 10/07/2020 ACEPTADO: 26/08/2020 PUBLICADO: 15/10/2020

1. Médico de la Universidad Católica de Cuenca; Clínica San Francisco; Guayaquil; Ecuador; jonathanmacas_24@hotmail. com; (iD https://orcid.org/0000-0002-2159-259X

2. Médico de la Universidad de Guayaquil; Investigador Independiente; Guayaquil, Ecuador; www.lisa288@hotmail.com; https://orcid.org/0000-0003-3403-6995

3. Médico de la Universidad Católica de Cuenca; Investigador Independiente; Guayaquil, Ecuador; xavier_honores@hotmail. es; (iD https://orcid.org/0000-0003-2512-3173

4. Médica; Hospital María Lorena Serrano; El Guabo, Ecuador; carolinalazo92@gmail.com; (iD https://orcid.org/0000-00033337-6242

\section{CORRESPONDENCIA}

Jonathan Alexander Macas Noblecilla

jonathanmacas_24@hotmail.com

Guayaquil; Ecuador 


\section{RESUMEN}

Las encefalitis autoinmune derivan de la inflamación o disfunción de algunas partes del cerebro causada por anticuerpos contra antígenos cerebrales específicos, y que generalmente tienen una presentación clínica con sintomatología psiquiátrica que muchas veces complica el diagnóstico oportuno para poder dar inicio a terapias inmunosupresoras. La encefalitis por anticuerpos anti NMDARes másfrecuente en casos de niños y adultos jóvenes, y se caracterizar por la presencia subagudade trastornospsiquiátricos, alteración de la conciencia, crisis epiléptica, entre otros (Erazo, 2019). En el presente informe se describe un caso de encefalitis autoinmune anti-receptor NMDA en adulto masculino de 31 años, con un cuadro caracterizado por trastorno del nivel de conscienciaconfundiendo las primeras impresiones diagnósticas donde es inicialmente asistido. Después de 15 días de presentación del cuadro clínico, finalmente es tratado en el Hospital Clinica Alcivar en Guayaquil, donde es ingresado a $\mathrm{UCl}$ requiriendo ventilación mecánica y plasmaféresis como parte del tratamiento que involucraba varios anticomiciales, y que después de casi dos meses de atención intensiva, sufre una crisis tónico clónica generalizadamúltiplerefractaria al tratamiento, por lo que se le induce a un coma barbitúrico, y se incluye Rituximabcomo nuevo tratamiento inmunosupresor. PALABRAS CLAVES: Encefalitis, Encefalitis Autoinmune, Encefalitis antí-NMDAR.

Palabras clave: Encefalitis, Encefalitis Autoinmune, Encefalitis antí-NMDAR.

\section{ABSTRACT}

Autoimmune encephalitis derives from the inflammation or dysfunction of some parts of the brain caused by antibodies against specific brain antigens, and which generally have a clinical presentation with psychiatric symptoms that often complicate the timely diagnosis to be able to start immunosuppressive therapies. Anti-NMDAR antibody encephalitis is more common in children and young adults, and is characterized by the subacute presence of psychiatric disorders, altered consciousness, and epileptic seizures, among others (Erazo, 2019). This report describes a case of anti-NMDA receptor autoimmune encephalitis in a 31-year-old male adult, with a condition characterized by a disorder of the level of consciousness, confusing the first diagnostic impressions where it was initially attended. After 15 days of presentation of the clinical picture, he is finally treated at the Hospital ClinicaAlcivar in Guayaquil, where he is admitted to the ICU requiring mechanical ventilation and plasmapheresis as part of the treatment that involved several anticonvulsants, and that after almost two months of intensive care, suffers a multiple generalized tonic clonic crisis refractory to treatment, for which he is induced to a barbiturate coma, and Rituximab is included as a new immunosuppressive treatment.

Keywords: Encephalitis, Autoimmune Encephalitis, Anti-NMDAR Encephalitis.

\section{RESUMO}

A encefalite autoimune deriva da inflamação ou disfunção de algumas partes do cérebro causada por anticorpos contra antígenos cerebrais específicos e que geralmente têm uma apresentação clínica com sintomas psiquiátricos que muitas vezes complicam o diagnóstico oportuno para iniciar terapias imunossupressoras. A encefalite com anticorpos anti-NMDAR é mais comum em crianças e adultos jovens e é caracterizada pela presença subaguda de transtornos psiquiátricos, consciência alterada e crises epilépticas, entre outros (Erazo, 2019). Este relato descreve um caso de encefalite autoimune anti-receptor NMDA em um adulto do sexo masculino de 31 anos, com quadro caracterizado por distúrbio do nível de consciência, confundindo as primeiras impressões diagnósticas onde foi atendido inicialmente. Após 15 dias de apresentação do quadro clínico, é finalmente tratado no Hospital ClinicaAlcivar de Guayaquil, onde é internado na UTI com necessidade de ventilação mecânica e plasmaférese como parte do tratamento que envolveu vários anticonvulsivantes, e que após quase dois meses de na terapia intensiva, sofre múltiplas crises tônicas clônicas generalizadas refratárias ao tratamento, para as quais é induzido ao coma barbitúrico, e o Rituximabe é incluído como novo tratamento imunossupressor.

Palavras-chave: Encefalite, Encefalite Autoimune, Encefalite Anti-NMDAR. 


\section{Introducción}

La encefalitis autoinmune anti-receptor NMDA es una compleja enfermedad, caracterizada por múltiples sintomatología, con alto riesgo de complicaciones, y un extenso abanico de diagnóstico diferencial. Los pacientes que la padecen, con mucha frecuencia son mal diagnosticados con un trastorno psicótico agudo, y al aparecer complicaciones y sintomatología que no encaja, son referidos a otras especialidades2. Es inexacta la incidencia de las encefalitis autoinmunes, ya que se ha reportado un alza epidemiológica en los último 10 años a raíz de los avances en las investigaciones de anticuerpos contra diferentes antígenos celulares (Pruss \& Stoecker, 2010). Sin embargo se ha podido observar que la frecuencia en centros especializados es más elevada que la de cualquier causa viral, además, en un 38 a 50\% de los casos se ha asociado a neoplasia oculta, en aproximadamente el $50-58 \%$ el más frecuente es el teratoma de ovarioen mujeres adultas, y en $5 \%$ el carcinoma de células germinales en varones (Dalmau, LancasterE, \& et al, 2011).

La encefalitis autoinmune es un síndromes neurológicos de presentación subaguda caracterizado por alteración de conciencia, de la memoria y por trastornos psiquiátricos que frecuentemente que vienen acompañado de posturas atípicas y crisis epilépticas consecuencia de la acción de anticuerposanti neuronales específicos, los cuales se fijan a proteínas de membrana o a receptores de neurotransmisores (Erazo, 2019). Según el tipo de inmunidad y antígeno que presente, se pueden subdividir en:

- Contra antígenos de superficie celular producida por anticuerpos: donde estos se comportan como agentes patógenos produciendo alteración en las funciones de proteínas de membranas y receptores. Tal es el caso de la encefalitis anti receptor de N-metil-D aspartato (R-NMDA), asociados regularmente a neopla- sias sistémicas (Varley \& Taylor, 2017).

- Contra antígenos intracitoplasmático: Está relacionado con la inmunidad celular, y generalmente está asociada a tumores. Tal es el caso de la encefalitis anti núcleo neuronal tipo 1 y tipo 2 (ANNA-1 y 2) o anti Hu y anti Ri (Varley \& Taylor, 2017).

- Contra antígenos aún no esclarecidos: tales como la encefalomielitis, la encefalitis lúpica y encefalitis Hashimoto (Varley \& Taylor, 2017).

En este reporte se presenta un caso de encefalitis autoinmune anti-receptor NMDA en adulto masculino, cuyo cuadro caracterizado por trastorno del nivel de consciencia, confunde las primeras impresiones diagnósticas de los criterios médicos donde es inicialmente asistido. Tras 15 días de evolución del cuadro, finalmente es tratado en el Hospital Clinica Alcivar en Guayaquil, donde fue ingresado en $\mathrm{UCI}$ durante un período de casi dos meses. Se plantea como caso de interés clínico por su no común incidencia, y por su nivel de atención y las diferentes terapias requeridas.

\section{Presentación del caso}

Paciente masculino de 31 años de edad, oficinista sin antecedentes patológicos de interés, es llevado por familiares al Hospital IESS de Machala por presentar alteración de la consciencia e irritabilidad. Permanece hospitalizado por tres días con el mismo cuadro, por lo que los familiares solicitan el alta. Debido a la manifestación de agresividad en su domicilio, los familiares concurren con el paciente nuevamente al Hospital IESS de Machala, donde es referido al Hospital IESS Cuenca para tratamiento psiquiátrico. En esta institución es contrareferido a Machala porque no se presentó ningún examen de imagen y laboratorio que descartara causa orgánica, por lo que los familiares deciden recurrir a la asistencia privada del Hospital Clínica Alcivar en Guayaquil, refiriendo que no se contaba con disponibili- 
dad física.

Al ingreso en esta unidad hospitalaria, el paciente se encontraba en estado somnoliento, apático y poco colaborador durante la anamnesis. A través de los familiares se dedujo una evolución aproximada de 15 días de un cuadro clínico caracterizado por períodos de alteración del sensorio con manifestaciones de irritabilidad, y durante el cual ha estado ingiriendo tres antipsicóticos. A la valoración física el paciente presentó pupilasiscóricas reactivas; mucosas húmeda; sin presencia de ingurgitación yugular; campos pulmonares ventilados adecuadamente con $98 \%$ de saturación al ambiente; ritmos cardíacos normales, sin evidencia de soplos, ni ruidos agregados a la auscultación; presión arterial 115/75 mmHg, con frecuencia cardíaca 90ppm; abdomen blando depresible no doloroso a la palpación con ruidos hidroaereos presentes, extremidades simétricas no edematizadas.

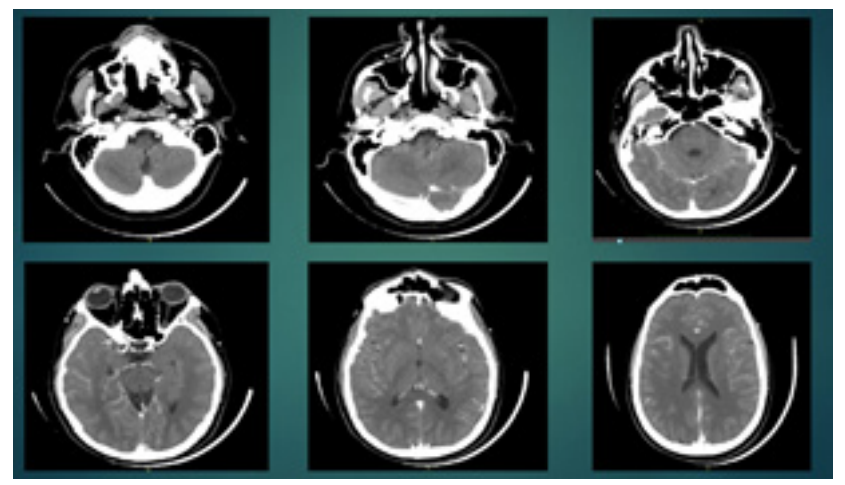

Imagen 1. Tac simple con contrastada de Craneo 15/11/2019

\section{Fuente: Los autores}

Nota: Sin lesiones agudas sin captacion anormal del medio de contraste.

Se ingresa a la Unidad de Cuidados Intensivos (UCl) con un diagnóstico de trastorno congnitivo en estudio y sospecha de neuroinfección, y se inician los exámenes pertinentes de imagenología, citología de líquidocefalorraquídeo (LCR), y laboratorio, incluyendo VIH, sífilis, exámenes de cocaína, marihuana yopiáceos en orina, los cuales resultaron negativos, así mismo laPCR de herpes virus y enterovirus. La mayoría de los resultados de los exámenes estuvieron en el rango normal exceptuando la creatina fosfocinasa (CPK>1787UL-1), la tomografía simple y contrastada de cráneo no evidenció lesión estructural (Figura 1). Se toman las medidas generales de cuidado crítico incluyendo recolocación de sonda nasogástrica y vesical con sus medidas de cuidado y mantenimiento.
Al tercer día de ingreso en la unidad intensiva, el paciente evidencia un alza de temperaturay respuesta inflamatoria, por lo que se inicia antibioterapia. Reportó a los días picos febriles, por lo que se cambia a terapia antibiótica de amplio espectro, lográndose disminuir los marcadores infecciosos después de una semana. El citológico delíquido cefalorraquídeo no permitió pensar en proceso infeccioso cerebral (LCR leucocitos 134 a predominio mononuclear, glucosa 8, proteína 45cls).

paciente evolucionóhacia un cuadro clínico caracterizado por estupor, con movimientos involuntarios en cavidad oral y abdominal,taquicardia y desaturación conestridor laríngeo superior y sialorrea, por lo que se procedió a realizar orointubación. En

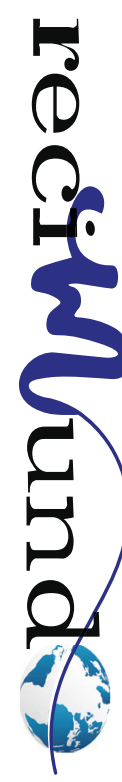


resonancia magnética de difusión (MRI) protocolo de epilepsia, se evidencia lesión activa de sustancia blanca a nivel frontal derecho (figura 2), que sumado al electroencefalograma (EEG), el cual reportó ritmos de base lentos multifocal, hizo pensaren posible encefalitis. Se inicia como medida de diagnóstico diferencial, terapia con Aciclovir 500mg ev cada 8h, y se realiza estudio de antígenos neurales IgG en líquido céfalo raquídeo, con sospecha diagnóstica de encefalitis de etiología autoinmune.

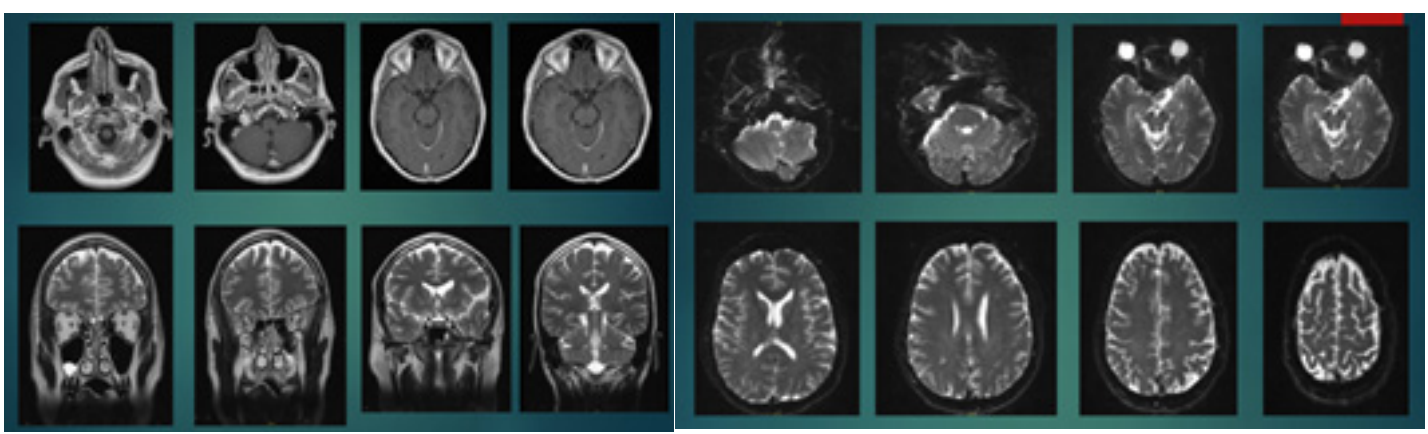

Imagen 2. Resonancia Magnética de Difusión (MRI) Cerebral-18/11/2019

Fuente: Los autores

Nota: Se evidencia una atrofia de hipocampos. Un quiste de plexo coroideo en asta occipital de ventrículo derecho.

Tras eventos de crisis comicial,con pleocitosis en LCR, y en espera de resultados de prueba diagnóstica para tipo de encefalitis, se valora al paciente en interconsulta de neurología, indicándose terapia anticonvulsivantes (Levetiracetam $1.5 \mathrm{~g} /$ día iv, Ac. Valproico 1000 mg/ díasngFenitoina 125 mg/díaiv ), plasmaféresis por 5 días, corticoterapiay controles de EGG y MRI. Después de una semana en $\mathrm{UCl}$, el paciente ya no presenta actividad epileptogénica posterior a inmunoglobulina. Finalmente se actualizó el diagnóstico de ingreso a UCl a Encefalitis Autoinmune (Anticuerpos anti NMDA en LCR $(+)$ ), como se muestra en la figura 3:

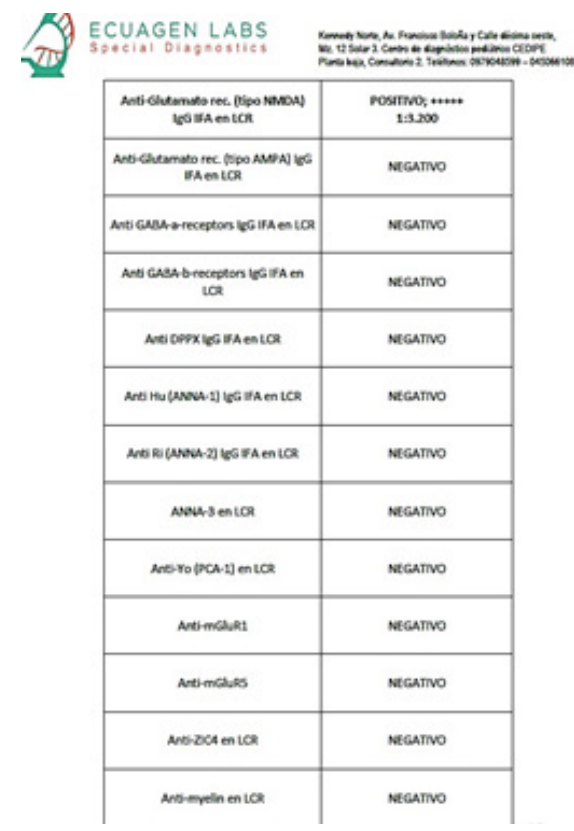

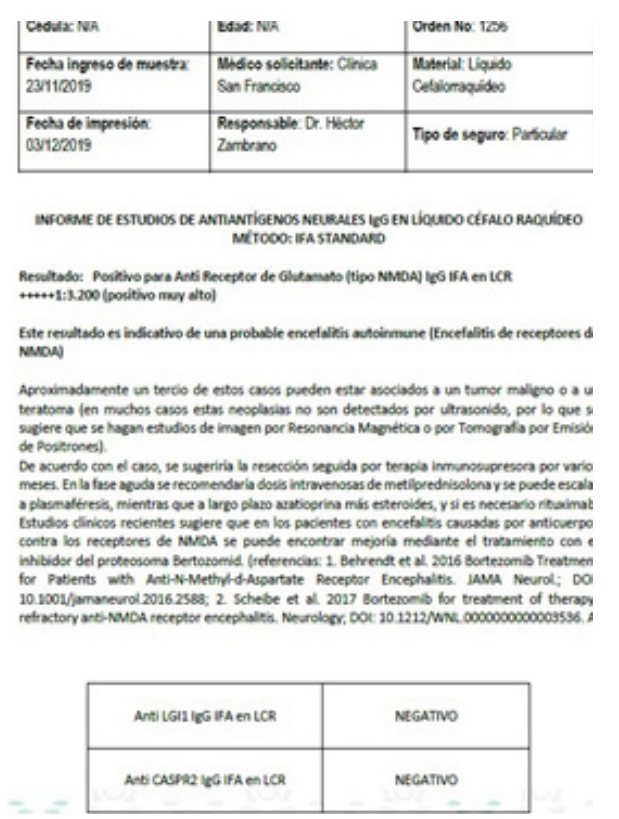

Imagen 3. Estudio de Antígenos Neurales IgG en Líquido Céfalo Raquídeo-23/11/2019 
No obstante, el paciente evolucionó tórpidamente, permaneció en sedación y analgesia con ventilación mecánica asistida controlada (presionpi $10 \mathrm{fr} 12$ peep 6 fio $45 \%$ ), cursando proceso infeccioso sobreañadidos. Y después de dos meses en cuidados intensivos, manifestó episodio de convulsiones tónico clónicas generalizadas corroboradas con EEG, por lo que se replanteó una nueva terapéutica: Levetiracetam $1.5 \mathrm{~g}$ IV TID, Ac. Valproico 1000mg SNG TID, Fenitoina 125mg IV BID, Lamotrigina 25mg am y 50mg pm por SNG. El paciente llegó al tope de dosis de sedación con Midazolam y Propofol, y aun recibiendo 4 tipos de anticomiciales, persistieron sus movimientos tónicos clónicos, por lo que se decidió iniciar Coma Barbitúrico, con el cálculo de 20mg/ $\mathrm{kg}$ como dosis de carga, y dosis de mantenimiento de $4 \mathrm{mg} / \mathrm{kg} / \mathrm{día}$. Se agrega a las indicaciones de $\mathrm{UCl}$, Rituximab de $375 \mathrm{mg} /$ $\mathrm{m} 2$ por cuatro semanas.

\section{Discusión}

Ante la falta de una de clínica que caracterice la encefalitis autoinmune anti-NMDA, se suele retrasar su diagnóstico, ya que la mayoría de ellas se presenta con un cuadro inicial psiquiátrico, donde el paciente presenta, generalmente, confusión, irritabilidad, mirada fija y movimientos distónicos oposturas catatónicas (Toledano, y otros, 2014). Esto sin contar las similitudes en los hallazgos clínicos de imagenología y laboratorio de muchas clases de encefalitis autoinmune e infecciosas (Dalmau, LancasterE, \& et al, 2011). Además, en este caso particular, resultó menos evidente el diagnóstico dado que se trataba de un adulto masculino de 31 años,cuando normalmenteesta suele relacionarse con la infancia o frecuentemente ocurrir en mujeres jóvenes y asociarsecon teratoma de ovario.

Aunque no existen tratamientos eficaz y definitivo en muchos casos de encefalitis (Wingfield, McHufh, Vas, \& et al, 2011), en especial la autoinmune anti-NMDA, es nece- sario hacer un diagnóstico etiológico. Hoy en día, se cuenta con guías diagnósticas para cada encefalitis, y según el criterio diagnóstico referido en la figura 4 , en este caso presentado se cumplió con el manejo más adecuado en el proceso diagnóstico y diferencial, basado la sintomatología neuropsiquiátrica típicas de encefalitis límbica, agregando reducción del lenguaje hasta llegar al mutismo, y en la disminución de la consciencia, disquinesiasfaciales, presentando crisis comicialcomplejas, incluso estados epilépticos. Además la resonancia magnética de cerebro no agregó mayor hallazgo, los electroencefalograma (EEG) fueron anormales en la mayoría de las veces realizado, y aunque inicialmente el LCR no fue concluyente, luego evidenciópleocitosis. Mientras se descartaban otras posibles etiologías, y se esperaba la confirmación de presencia de AC IgG anti R Glu N1 de NMDA 1, se realizó pronóstico profiláctico potenciales, y asesoramiento de los familiares.

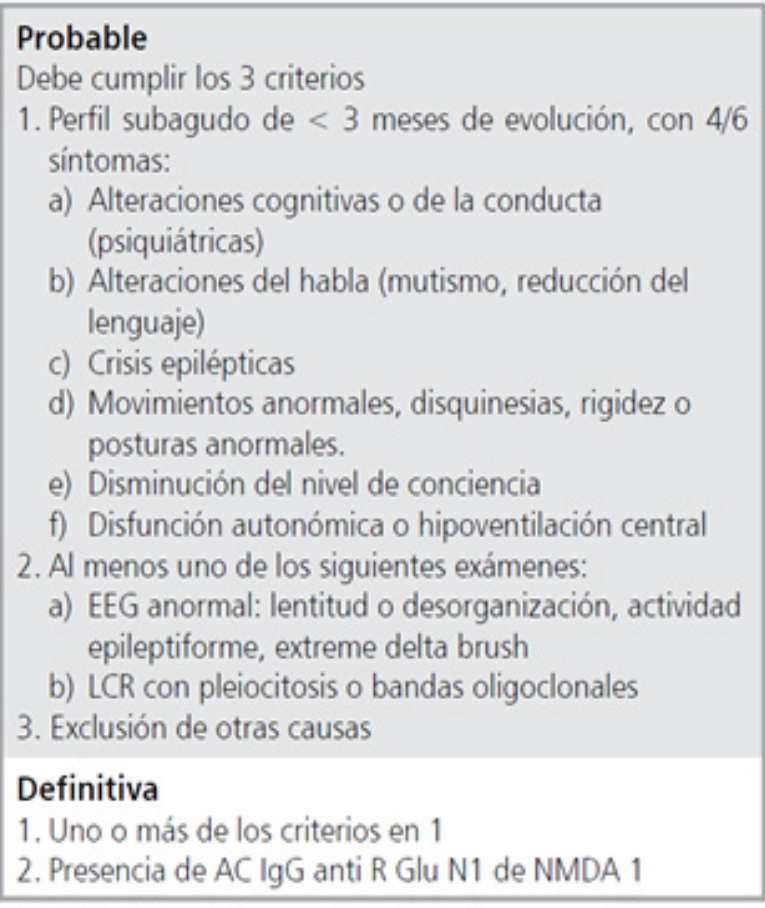

*LCR: Líquido cefalorraquídeo; EEG: Electroencefalograma.

Imagen 4. Criterios diagnósticos para encefalitis por anticuerpos anti R-NMDA

Fuente: (Graus, Titulaer, Balu R, \& et al, 2016) 
En el diagnóstico diferencial sirvieron los exámenes de imágenes en busca de lesiones cerebrales para descartar trastornos autoinmune, lo que de inmediato fue descartado en la primera impresión. Para exclusión de origen infeccioso se realizaronexámenes de laboratorio, incluyendo VIH, sífilis, PCR de herpes virus y enterovirus, citología de líquido cefalorraquídeo (LCR). Mientras se hacían pruebas, de manera empírica se cubrió con terapias antibióticas y antivirales (Aciclovir), cualquier proceso de etiología infecciosa. Y para descartar otrasposibles causas neurológicas se realizaron exámenes de cocaína, marihuana y opiáceos en orina. Aunque ya el pronóstico médico sospechaba de una encefalitis autoinmune, era necesaria la confirmación de la misma descartando los otros tipos de encefalitis y confirmando la presencia del anti NMDA, como se observa en la figura 3.

El tratamiento suele ser agresivo pero la evolución natural de la enfermedad sugiere que ciertos pacientes prolongan este curso, y a veces pueden manifestar una mejoría neurológica espontánea. Generalmente, se necesitan de 3-4 meses de hospitalización para la recuperación, pero para este caso en particular, el paciente ingresa a $\mathrm{UCl}$ y su estado se va complicando no sólo con la patología misma sino con infecciones añadidas por la misma estancia en UCI, Ilegando hasta una franca recaída y falta de re respuesta al tratamiento indicado, a tal punto que requirió una inducción al coma barbitúrico y añadir a las indicaciones el Rituximab. Es algo notorio en este caso, dado que en promedio las recaídas por encefalitis contra los receptoresanti-NMDAson relativamente bajos (20-25\%) (Wingfield, McHufh, Vas, \& et al, 2011).

\section{Conclusión}

En el abordaje del paciente con encefalitis, se debe hacer un intento deestablecer un diagnóstico etiológico e identificar unagente específico ya que podría ser importante para el pronóstico, la profilaxis e intervenciones médicas.

Para ello, hay que tomar en cuenta que las convulsiones tienden a ser una constante en la encefalitis autoinmune, lo que le hace unsíntoma característico de importancia. Además, en la encefalitis anti-NMDAR, las convulsiones pueden ocurrir encualquier etapa de la evolución enfermedad por lo que se amerita un seguimiento adecuado.

A partir de este caso se puede recomendar que ante un cuadro caracterizado por la alteración de laconducta, conocimiento o disminución de conciencia de forma aguda, en adulto, con una evolución de 10 días en promedio, se debe considerar el diagnóstico de encefalitis anti-receptorNMDA.

\section{Bibliografía}

Dalmau, J., LancasterE, \& et al. (January de 2011). Clinical experience and laboratory investigations in patients with anti-NMDAR encephalitis. Lancet Neurol, 10(1), 63-74.

Erazo, R. (2019). Encefalitis Autoinmunes. Receptor Anti-NMDA y nuevos inmufenotipos. Medicina, 79(3), 54-59.

Graus, F., Titulaer, M., Balu R, \& et al. (2016). A clinical approach to diagnosis of autoinmune encephalitis. Lancet Neurol, 15(4), 391-404.

Landa, E., Alvites, M., Fortes, J., \& Pérez, M. (2015). Psicosis y encefalitis NMDA: reporte de un caso y revisión de la litaratura. REV CLíN MED FAM, 8(1), 75-78.

Pruss, H., \& Stoecker, W. (Noviembre de 2010). Retrospective analysis of NMDA receptor antibodies in encephalitis of unknown origin. Neurology, 75(19), 1735-1739.

Toledano, M., Britton, J., McKeon, A., Shin, C., Lennon, V., \& et. al. (2014). Utility of an immunotherapy trial in evaluating patients with presumed autoimmune epilepsy. Neuroly, 157, 1578-1586.

Varley, J., \& Taylor, J. (2017). Neuropharmacology Autoantibody-mediated diseases of the CNS: Structure, dysfunction and therapy. (A. SRI, Ed.) Neuropharmacology.

Wingfield, T., McHufh, C., Vas, A., \& et al. (2011). Autoimmune encephalitis: A case series and comprehensive review of the literature. QJM, 104, 921931. 


\section{CITAR ESTE ARTICULO:}

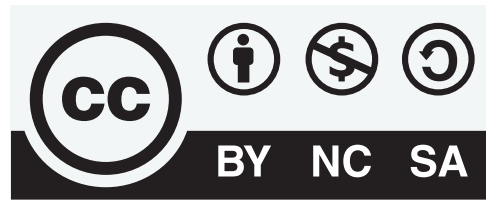

CREATIVE COMMONS RECONOCIMIENTO-NOCOMERCIAL-COMPARTIRIGUAL 4.0.

Macas Noblecilla, J. A., Muñoz Rodríguez, L. L., Honores Correa, A. X., \& Lazón Amon, J. C. (2020). Encefalitis autoinmune por anticuerpos NMDA a propósito de un caso clínico. RECIMUNDO, 4(4), 174-181. https://doi.org/10.26820/recimundo/4.(4).octubre.2020.174-181 